\title{
Research on Investigation into Mental Health of Physical Education Teachers from 18 Middle Schools in Wuhan
}

\author{
Qian Jianlong \\ Physical Education College of Jianghan University \\ Wuhan, China, 430056 \\ Email:qjljcg@126.com
}

\author{
Gao Si \\ Department of physical education, Zhongnan University \\ of Economics and Law \\ 1549405068@qq.com
}

\begin{abstract}
This paper analyzes the mental health level of 65 PE teachers from 18 middle schools by means of the psychological measurement SCL-90 (symptom check list-90), mathematical statistics and literature data. The aim is to find out the mental health level of PE teachers in middle school and its related factors. The results show that gender, age and school types are correlated with the mental health status of PE teachers. Some constructive suggestions are put forward to improve the mental health of middle school teachers.
\end{abstract}

Keywords-Wuhan city; Middle school physical education teachers; Mental health; Investigation and research

\section{INTRODUCTION}

There are two viewpoints on the mental health problems of teachers in foreign studies. One is that teachers engaged in education do not have more mental illness than those engaged in other occupations. The other is that teachers not necessarily show more mental health than other occupations in terms of occupational and life adaptation. In the United States, according to many objective data, at least $6-8 \%$ of teachers have different degrees of maladjustment. This figure is close to the number of employees with mental illness in other industries, but due to the profound influence of teachers' personality on students, the problem of teachers' mental health is worthy of attention. Professor Solomon said, "in terms of individual personality development, teachers are second only to parents. If a child has both a sweet family, enjoying the love of parents, and a teacher of physical and mental health, it is extremely happy. On the contrary, if a child cannot get enough care and love from his parents, and he is unreasonably troubled by a teacher who is emotionally unstable, many problems of physical and mental development will appear for him." Traver and Cooper (1993) find that teachers have a higher level of stress than the general population such as doctors, nurses, hospital attendants, etc.; According to a survey in the Netherlands, teachers think they have the greater workload than workers. A preliminary study on the stress of young teachers in China by Shao Guanghua and Gu Lingyuan (2002) shows that the teaching profession is a profession with high stress level [1]. Hong Kong once ranked teacher pressure second only to the police. At present, the incidence of mental disorders among normal people in China is about $20 \%$, while the incidence of teachers surveyed is as high as 52\%. In 2000, the national mental health education research group for primary and middle schools conducted a sample survey of 1191 teachers from 168 urban and rural primary and secondary schools in 14 cities of Liaoning Province. The results show that $51.23 \%$ of the teachers have psychological problems, where $32.18 \%$ of them have mild mental disorder, and $2.49 \%$ even have mental illness. Therefore, the mental health of teachers is not optimistic. As both physical workers and intellectual laborers, physical education teachers are a special group of teachers. This paper takes 65 middle school PE (physical education) teachers in Wuhan as the research object and analyzes their physical and mental health status and characteristics from the aspects of gender, age and school types.

\section{RESEARCH OBJECTS AND METHODS}

\section{A. Research objects}

A total of 65 PE teachers from 18 middle schools in Hankou, Hanyang and Wuchang of Wuhan City are chosen, where there are 53 male teachers and 12 female ones, 27 teachers aged 25 to 35 , and 29 teachers aged 36 to 45 years or over, 65 with the bachelor degree, as well as 1 with the junior college degree.

\section{B. Research methods}

Psychological measurement: SCL-90, the mental health self-rating scale, contains nine factors, including physical symptoms, interpersonal relationships, depression, anxiety, hostility and so on.

Questionnaires: investigate the PE teachers' information including sex, age, educational background, years of working and sports years.

Mathematical statistics: analyze the research data by the method of sports statistics.

Literature analysis: retrieve and collect more than 60 related documents to demonstrate the research subject. 


\section{RESULTS AND ANALYSIS}

\section{A. The general level and analysis of PE teachers' mental} health in middle schools

The results of SCL-90 test show that (see Table 1) there are significant differences between the psychological status of PE teachers in middle schools and the national norm. PE teachers' somatization and depression are greater than the national norm's. PE teachers often exercise, but excessive exercise can also lead to physical injuries. In the questionnaire, most PE teachers have low back pain, muscle soreness and joint pain. Sports injuries are basically the result of the training in college and physical education. Although PE teachers have sports injuries, their cardiopulmonary function is better than other teachers. As to psychological problems from depression, its possible reasons can include the school's strict educational management system, teaching reform and transformation, school integration, post adjustment, the achievement motivation, evaluation, inspection and other factors, which can produce psychological pressure. If such pressure is not resolved, anxiety and depression can easily occur.

TABLE I. COMPARISON BETWEEN THE MEAN VALUES OF SCL-90 FACTORS FOR SOME MIDDLE SCHOOL PE TEACHERS IN WUHAN AND THE NATIONAL NORM

\begin{tabular}{cccc}
\hline Factors & Middle School Teachers $(\mathrm{n}=65)$ & National Norm(n=1388) & $\mathrm{P}$ \\
\hline Somatization & 1.508 & 1.37 & $<0.05$ \\
Obsessive- & & & $>0.05$ \\
compulsive & 1.269 & 1.62 & $<0.05$ \\
Symptoms & & & $<0.05$ \\
Interpersonal & 1.69 & 1.65 & $>0.05$ \\
Relation & 1.506 & 1.5 & $>0.05$ \\
Depression & 1.103 & 1.39 & $>0.05$ \\
Anxiety & 0.689 & 1.46 & $>0.05$ \\
Hostility & 0.737 & 1.23 & $>0.05$ \\
Horror & 0.711 & 1.43 & 1.29 \\
Delusion & 1.057 & & \\
Mental Symptoms & & & \\
\hline
\end{tabular}

B. Comparative analysis on mental health of middle school PE teachers with different genders

The statistics of mental health of middle school PE teachers with different genders (Table 2) show that the mean value of interpersonal relation and depression for the male PE teacher is higher than those of the female PE teachers. Obsessivecompulsive symptoms, anxiety, hostility, horror, delusion and mental symptoms are significantly higher for the female PE teachers than the male PE teachers. The mental health of the female teachers can be affected by the following factors: first, the influence of traditional concepts on women's role; second, the psychological imbalance caused by unfair competition; third, emotional frustration caused by marital disharmony; fourth, great mental pressure leading to early aging. In the aspects of the social role, physiological structure and individual value realization, the female teachers pay more effort than male teachers to be recognized. But happily, compared with other teachers, the female PE teachers have a higher level of mental health, a positive and optimistic thinking, and the ability to objectively analyze problems. This also shows that physical exercise can cultivate sentiment and adjust mental health.

TABLE II. COMPARISON BETWEEN THE MEAN VALUES OF SCL-90 FACTORS FOR SOME MIDDLE SCHOOL PE TEACHERS WITH DIFFERENT GENDERS IN WUHAN

\begin{tabular}{cccc}
\hline Factors & Male $(\mathrm{n}=53)$ & Female $(\mathrm{n}=12)$ & $\mathrm{P}$ \\
\hline Somatization & 15 & 15.42 & $>0.05$ \\
Obsessive-compulsive & 12.6 & 12.92 & $>0.05$ \\
Symptoms & 10.57 & 10.12 & $>0.05$ \\
Interpersonal Relation & 14.89 & 14.33 & $<0.05$ \\
Depression & 10.96 & 11.33 & $>0.05$ \\
Anxiety & 6.83 & 7.25 & $<0.05$ \\
Hostility & 7.34 & 7.5 & $<0.05$ \\
Horror & 7.02 & 7.5 & $>0.05$ \\
Delusion & 10.55 & 10.67 & $>0.05$ \\
Mental Symptoms & &
\end{tabular}




\section{Comparative analysis of mental health of middle school $P E$ teachers with different ages}

Through multiple comparison analysis, it is found that the PE teachers aged 36 to 45 years old are higher in somatization, interpersonal relationship, anxiety, horror and delusion than the teachers with other two age stages. Anxiety and horror are the main contents of this factor. The growth experience of a PE teacher is as follows: the pre-service period $\rightarrow$ the initial period $\rightarrow$ the capacity-building period $\rightarrow$ the enthusiasm and growth period $\rightarrow$ the career frustration period $\rightarrow$ the stable career period $\rightarrow$ the career retreat period $\rightarrow$ the dimission period. Middle-aged PE teachers are in "the career frustration period", which is full of stress and leads to burnout. Maslach thinks that career burnout is a psychological state composed of three dimensions, namely, emotional exhaustion, depersonalization and reduced sense of achievement. Teachers' career burnout is an extreme reaction when teachers can not cope with work stress smoothly. It is a state of exhaustion in emotion, attitude and behavior produced by the long-term stress experience. The typical symptoms of the career burnout include low job satisfaction, loss of work enthusiasm and interest, as well as emotional alienation and apathy [8]. At the same time, The PE teacher, as a special profession, has both the teaching characteristics of general teachers and its own work characteristics-outdoor teaching and many physical activities [9]. With the increase of age, the physique of most PE teachers will gradually decline, so many action demonstrations are not as flexible and easy to complete as before, and their physical and mental fatigue is also easy to appear and difficult to recover. The main reasons for these psychological problems are as follows: the decrease of teaching enthusiasm, the lack of communication with students, the phenomenon that some students do not respect teachers, and the school administrators not paying enough attention to physical education, thereby not fully reflecting the teachers' self-worth. In the 25-36 age, PE teachers belong to the initial period, the capacity-building period and the enthusiasm and growth period. The teachers strive to improve their professional knowledge and ability to work, seek out new teaching materials, methods and strategies, participate actively in colloquiums, care for students and want to communicate with them, seek the recognition of colleagues and teaching leaders, as well as try to reach a comfortable and safe level in dealing with daily problems and affairs. They see work as a challenge. The teachers over the age of 46 have slowly entered a career retreat period, but there are also concerns about uncertainty of their future lives.

TABLE III. COMPARISON BETWEEN THE MEAN VALUES OF SCL-90 FACTORS FOR SOME MIDDLE SCHOOL PE TEACHERS WITH DIFFERENT AGES IN WUHAN

\begin{tabular}{ccccc}
\hline Factors & $\begin{array}{c}25-35 \text { Years } \\
\text { Old(n=27) }\end{array}$ & 36-45 Years Old(n=29) & $\begin{array}{c}\text { Over 46 Years } \\
\text { Old(n=9) }\end{array}$ & $P$ \\
\hline $\begin{array}{c}\text { Somatization } \\
\text { Obsessive- }\end{array}$ & 14.81 & 15.58 & 14.89 & $<0.05$ \\
compulsive & 13.24 & 12.41 & 12.33 & $<0.05$ \\
$\begin{array}{c}\text { Symptoms } \\
\text { Interpersonal }\end{array}$ & 10.65 & 10.82 & & $>0.05$ \\
Relation & 14.67 & 15.56 & 9.89 & $<0.05$ \\
Depression & 10.93 & 11.41 & 15.17 & $>0.05$ \\
Anxiety & 7.29 & 6.76 & 10.78 & $<0.05$ \\
Hostility & 7.37 & 7.55 & 6.56 & $>0.05$ \\
Horror & 7.18 & 7.31 & 7.11 & $<0.05$ \\
Delusion & 10.78 & 10.41 & 6.56 & $>0.05$ \\
Mental & Symptoms & & 10.44 & \\
\hline
\end{tabular}

\section{Difference comparison of mental health of PE teachers} from middle school with different types

The analysis of PE teachers from middle school with different types show that PE teachers from non-key schools are higher in factors such as somatization, obsessive-compulsive symptoms, interpersonal relationships, hostility, delusion and mental symptoms than those from district and provincial key schools, while in terms of depression, anxiety and horror, the latter is higher than the former. At the same time, the mean values of SCL-90 factors of PE teachers in key and non-key schools are higher than those of the teachers from secondary schools. For the investigated key schools, most of which pay attention to admissions rates, physical education lessons are often occupied by other lessons, which has hit the teaching enthusiasm of PE teachers to a certain extent. In addition, the idea of not paying attention to physical education can also be clearly reflected in the parents of children from key schools. For the above two reasons, PE teachers in key schools have no enthusiasm for physical education teaching, own a good teaching environment which can not be fully utilized, can not do their best to give play to the studied major, as well as can not find their own interest and value, easy to produce psychological problems. Students in non-key schools have a relatively low financial level at home, and most of their parents are very supportive of the schools' recreational and sports activities, hoping that their children can learn more about all kinds of knowledge and skills. However, the sports facilities and economic investment of non-key schools are obviously inadequate, so even though the PE teachers have enough enthusiasm and many innovations in teaching ideas, they can not be fully developed due to the constraints of the 
environment, thereby bringing about unhealthy psychological phenomena such as depression, hostility and delusion. Therefore, PE teachers from general schools also encounter the occupational psychological pressure from artificial and material conditions. According to the above two problems, the district key schools have both certain facilities and the attention of school leaders, so PE teachers from the district key schools have fewer mental problems than those from the other two types of schools.

TABLE IV. COMPARISON BETWEEN THE MEAN VALUES OF SCL-90 FACTORS FOR SOME PE TEACHERS FROM MIDDLE SCHOOLS WITH DIFFERENT TYPES IN WUHAN

\begin{tabular}{ccccc}
\hline Factors & $\begin{array}{c}\text { Provincial } \\
\text { Focus(n=25) }\end{array}$ & District Focus(n=20) & Non-Focus(n=20) & $\mathrm{P}$ \\
\hline $\begin{array}{c}\text { Somatization } \\
\text { Obsessive- }\end{array}$ & 15.2 & 13.75 & 16.25 & $<0.05$ \\
compulsive & 13.36 & 12.55 & 12.25 & $>0.05$ \\
Symptoms & & & & \\
Interpersonal & 10.48 & 9.8 & 11.2 & $<0.05$ \\
Relation & 16.48 & 14.7 & 14.9 & $<0.05$ \\
Depression & 12.16 & 10.8 & 11.1 & $>0.05$ \\
Anxiety & 6.88 & 6.8 & 6.9 & $>0.05$ \\
Hostility & 7.48 & 7.3 & 7.3 & $>0.05$ \\
Horror & 7.08 & 6.6 & 7.65 & $>0.05$ \\
Delusion & 9.28 & 9 & 9.7 & $>0.05$ \\
Mental & & & & \\
Symptoms & & & & \\
\hline
\end{tabular}

\section{RECOMMENDATIONS AND CONCLUSIONS}

\section{A. Conclusions}

The psychological problems of PE teachers from middle schools have become a common concern in schools and society. The mental health problems of PE teachers vary according to gender, age, and school environment. Therefore, the influence of PE teachers' mental health on students should be fully understood, and psychological adjustment should be conducted to maintain PE teachers' mental health.

\section{B. Recommendations}

School leaders and class teachers should strengthen their understanding of the promotion of health by physical education, and the nature of PE teachers' work.

PE teachers should have firm belief, and learn to relieve or ease their own bad emotions to deal with unpleasant things by means of autosuggestion regulation, activity regulation, incentive regulation, autocatharsis and other correct methods.
PE teachers should take in a wide range of knowledge, as well as care about, understand and respect for students

PE teachers should cherish their physical and mental health.

\section{REFERENCES}

[1] English - Chinese Journal of Light Industry Press, 2005 , (1)

[2] Wang Wenli, Zhang Chunwu, Zhang Cui Ping . Analysis of the mental health of PE teachers . Journal of Hebei Agricultural University. 2001 (12)

[3] Liu Changjiang, Wu Xinchun, Xiang Liu , The revision of the teacher's job burnout inventory. Psychological development and education. 2003(3)

[4] Zhang Xiaoling and Dong Xiuqin . Investigation report on mental health status of teachers in junior high school . Journal of Qingdao Vocational and Technical College. 2015 (6)

[5] Shen Zhengrong, Chen Long. Analysis of Teachers' Mental Health and Influencing Factors. Chinese Journal of Behavioral Medicine and Science. 2015 (4)

[6] Gao Daguang. Maintenance and Adjustment of Mental Health of PE Teachers . Journal of Inner Mongolia University of Nationalities . 2014 (2). 